\title{
AMS Purchase of MAA Press: The View From Acquisitions
}

\section{Sergei Gelfand and Stephen Kennedy}

On September 29, 2017, the AMS and the MAA announced an agreement to merge the book programs of the two societies. AMS purchased the book program from the MAA, retaining an ongoing collaborative partnership for the development of content for the book program. In many ways this marriage is a very natural arrangement; AMS Books and MAA Press were, before the partnership, two of the most prominent publishers of English-language mathematics books by and for mathematics professionals. Traditionally, of course, the two presses existed to serve the separate needs of research mathematicians and teaching mathematicians. If that divide ever really made sense, it has grown less significant over recent decades; AMS members have always been, and are increasingly, vitally involved in the teaching and learning of undergraduate mathematics, and MAA members have always had vigorous research careers and have in recent decades increasingly involved their undergraduate students in research. Our missions form a coherent whole and our joint books program reflects that-explain mathematics from the point of view of the professionals who know and love it.

Sergei Gelfand is the Publisher of the AMS and leads the Society's acquisitions efforts. His email address is sxg@ams. org.

Stephen Kennedy was the Senior Acquisitions Editor for MAA Press and now works for AMS as acquisitions specialist for MAA Press titles. His email address is kennedy.maapress@ams.org.

For permission to reprint this article, please contact: reprint - permission@ams.org.

DOI: https://dx.doi.org/10.1090/noti 1781
Both societies have, in recent years, been engaged in deliberate efforts to expand and diversify the types of books each produced. The MAA, leveraging its expertise in extraordinary exposition and pedagogy, has made a concerted effort to produce a full catalogue of widely adoptable undergraduate textbooks. The AMS, as a natural outgrowth of its long history of publishing excellent graduate textbooks (and up-to-the-minute monographs), has initiated an undergraduate textbook line and the expository Student Mathematics Library to bolster its catalogue of titles aimed at undergraduates. Simultaneously, AMS has begun an initiative to produce titles for the general public, including a remarkable collection of children's books and several volumes of Math Circle activities. With this growth came an increasing overlap of mission and a realization within the governance structures of both societies that we could be more effective working together by amplifying resonances and reducing redundancies. The marketing capabilities and the world-wide reach and reputation of the AMS give the MAA an extraordinary opportunity to put MAA books in front of an enormously larger market; the AMS gains increased visibility in the North American undergraduate mathematics world and a collection of nearly 300 titles in a market into which the Society hopes to expand.

Both the AMS and the MAA have long relied on volunteer editorial boards to ensure the quality of our books. That will not change with this new arrangement. AMS and MAA book series will continue to have editorial boards appointed by their respective governance structure. And those boards continue to be involved in evaluating and editing their respective manuscripts. The AMS book program at approximately 75 titles per annum pre-merger 
was significantly larger than the MAA's (12-15 books per year). Given the AMS's larger infrastructure, all business functions are now handled by AMS. The MAA Press imprint will be retained, and all MAA titles will bear both societies' imprints. The AMS will preserve the identities of the two presses, while seeking ways to grow both programs symbiotically. AMS employs an acquisitions specialist to take primary responsibility for MAA Press titles.

The publication of undergraduate textbooks is one of the most significant services to mathematics the AMS-MAA book program can provide. Both societies (and within AMS, the acquisitions team in particular) take that responsibility to the community extremely seriously. The commercial textbook market too often lets the professoriate down: with distressing frequency, prices are too high, quality control is slipshod, and editions are renewed with bewildering speed. Market forces seem to dictate what's available instead of the mathematical and pedagogical needs of students. To ameliorate these problems, each society publishes an undergraduate textbook series. We have each made a rigorous effort to maintain high quality of exposition and production while, simultaneously, trying to keep costs to students reasonable. The newly constituted AMS-MAA acquisitions team is engaged in an ongoing effort to obtain the highest quality textbooks possible for our textbook series. We are also attempting to preserve the distinct identities of the existing series: the AMS Pure and Applied Undergraduate Texts series will focus on upper-division courses for students primarily at research universities preparing for a professional career involving mathematics; the MAA Textbooks series will aim at the four-year college market and will include books for non-standard courses and books featuring innovative pedagogical strategies.

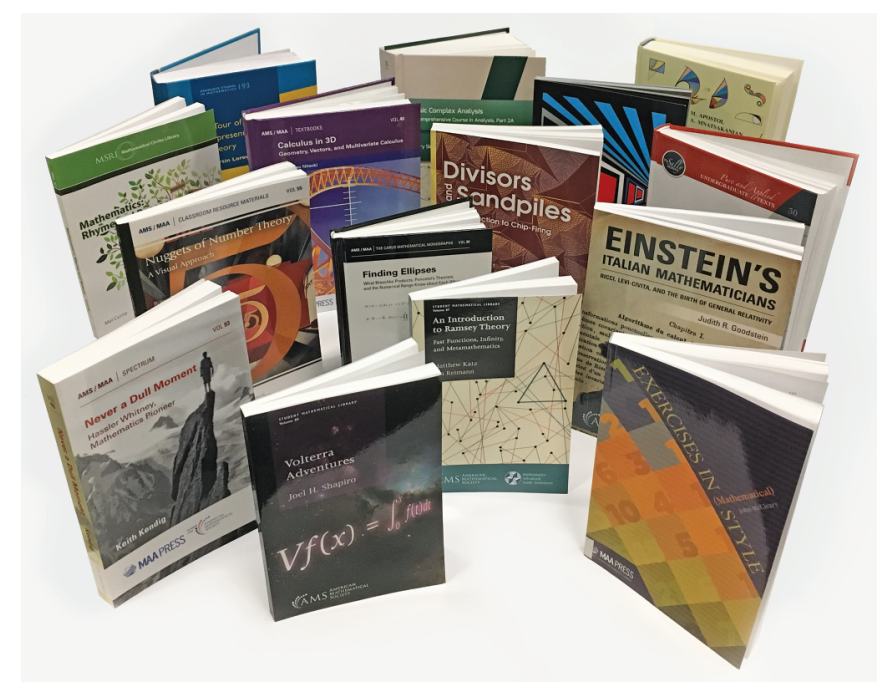

We'd like to take this opportunity to familiarize Notices readers with the MAA Press book catalogue. Besides the Textbooks series, there are six other MAA book series now published by AMS.

The MAA's three expository book series reflect the Association's historical commitment to accessible communication of mathematics. The Anneli Lax New Mathematical Library (NML) produces books primarily targeted at high school students and their teachers. Oleg Ivanov's Portal through Mathematics and The Riemann Hypothesis by Roland van der Veen and Jan van de Craats are typical volumes. The former is a collection of more than 200 puzzles and problems chosen for their capacity to surprise and delight; the latter was written to accompany a summer-enrichment course for advanced high school students. In spite of the intended target, it is often the case that NML volumes can be enjoyed by professionals; it is worth highlighting John McCleary's Exercises in (Mathematical) Style in this context: an homage to Raymond Queneau's Exercises in Style, it tells 99 stories of the binomial coefficients in a variety of voices, styles, and literary forms.

The Dolciani Mathematical Expositions aim to exposit areas of undergraduate mathematics in a way that can be appreciated by both professionals and students. Some typical titles are Larry Lehman's Quadratic Number Theory, Andy Simoson's Exploring Continued Fractions, and Ray Rosentrater's Varieties of Integration. Dolcianis can be used as textbooks; more often they provide enrichment reading for undergraduates or for faculty desiring to expand their understanding.

The Carus Mathematical Monographs is the MAA's Cadillac series featuring exquisite exposition for professionals. The most recent Carus is a beautiful example: Finding Ellipses by Ulrich Daepp, Pamela Gorkin, Andrew Shaffer, and Karl Voss is a surprising mélange of complex analysis, projective geometry, and linear algebra. The typical Carus is written at a level accessible to a reader with some exposure to graduate-level mathematics and is designed to beguile and induce that reader to further study.

The MAA's Classroom Resources Materials (CRM) series provides undergraduate faculty with a wide variety of materials to enrich their pedagogy. Some typical recent titles are Tactile Learning Activities in Mathematics by Julie Barnes and Jessica Libertini and the forthcoming Mathematics for Social Justice by Gizem Karaali and Lily Khadjavi. Both volumes contain a number of classroom-tested modules and activities that, in the former case, feature a physical component and, in the latter case, address an issue of social justice. Included in CRM are a number of possible textbooks featuring unusual content or pedagogy: Discovering Discrete Dynamical Systems by Johnson, Madden, and Sahin is a complete Inquiry-Based Learning course on discrete dynamics, while Introduction to the Mathematics of Computer 


\section{AMS COMMUNICATION}

Graphics by Nathan Carter is designed to accompany a firstyear college course on that topic.

MAA Problem Books are collections of contest problems and solutions usually accompanied by tips on succeeding in competitions. Typical volumes collect Putnam and American Mathematics Competitions problems. (Both competitions are organized by the MAA.) Notable in this series are James Tanton's Clever Study Guides, volumes on secondary topics for teachers and students organized around AMC problems.

Finally, Spectrum is the MAA series of volumes for recreational reading by professionals; it includes memoirs, history, biography, and the occasional piece of fiction. David Zitarelli's forthcoming history of mathematics in North America and Keith Kendig's biography of Hassler Whitney are representative.

The united presses of the MAA and the AMS, with our mutual ethic of service to the profession, intend to jointly continue our long histories of producing high quality mathematical monographs, textbooks, and expositions. As the world's largest mathematics publisher run completely by mathematicians we take very seriously our mission of protecting, preserving, and extending our subject. We aspire to publish the most significant works of mathematics, of mathematics pedagogy, and, more generally, of mathematical culture. The new joint acquisitions team of AMS and MAA consisting of the authors and our colleagues Eriko Hironaka and Ina Mette looks forward with excitement and enthusiasm to taking advantage of the resources and reputations of our two organizations to build the most prestigious and significant catalogue of mathematics books in the world. We invite you to participate in this effort by sending us your manuscripts, by adopting our textbooks, and by enjoying our books.

\section{Credits}

Photo of Sergei Gelfand is by Eric Buck.

Photo of Stephen Kennedy is courtesy of Stephen Kennedy. Photo of books in the AMS, AMS-MAA book programs is by Courtney Rose.

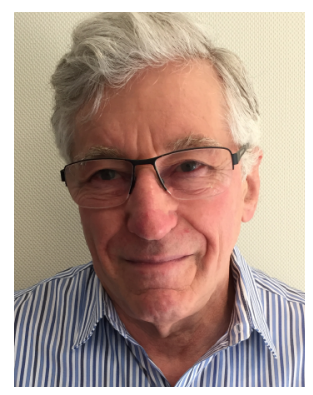

Sergei Gelfand

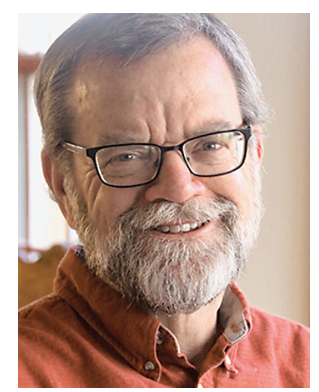

Stephen Kennedy

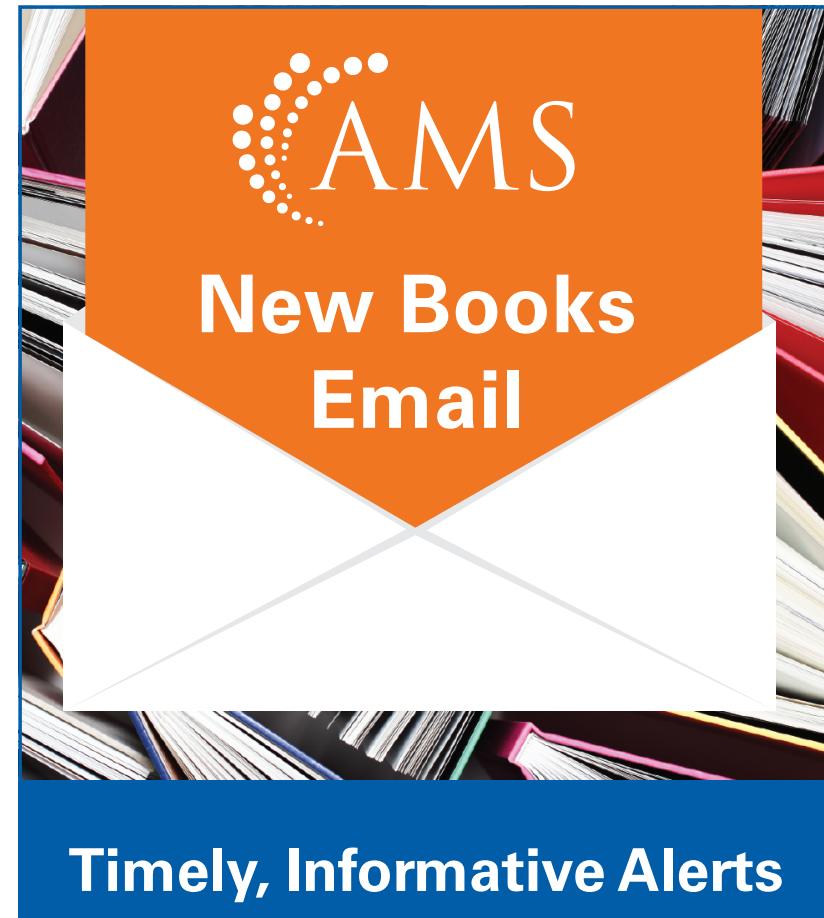

The AMS Bookstore New Books email alert is the best way to keep current with new developments in your field and learn about forthcoming and recently published titles. These monthly mailings allow you to:

- Access each book's abstract page on the AMS Bookstore

- Preview chapter samples, Tables of Contents, Indexes, and author supplemental materials

- Learn about Bookstore sales, special discounts, publishing highlights, and more

It's convenient, it's free, and you can unsubscribe at any time. Sign up today!

WWW.ams.org/ bookstore-email-list 